\title{
Cystic Lymphangioma on the Floor of the Oral Cavity Extending to the Submandibular Region in Adult Patients
}

\author{
Nadia M'jahad 1,2*, Najib Benmansour ${ }^{1,2}$, Abdelouahid Taleuan',2, Akammar Amal1,3, \\ Mustapha Maaroufi ${ }^{1,3}$, Mohamed Nourredine El Alami1,2 \\ ${ }^{1}$ Faculty of Medicine and Pharmacy, Sidi Mohammed Benabdellah University, Fez, Morocco \\ ${ }^{2}$ Department of Otorhinolaryngology (ENT) and Headneck Surgery, CHU Hassan II, Fez, Morocco \\ ${ }^{3}$ Department of Radiology, CHU Hassan II, Fez, Morocco \\ Email: *mjhdnadiaorl15@gmail.com
}

How to cite this paper: M'jahad, N., Benmansour, N., Taleuan, A., Amal, A., Maaroufi, M. and El Alami, M.N. (2020) Cystic Lymphangioma on the Floor of the Oral Cavity Extending to the Submandibular Region in Adult Patients. International Journal of Otolaryngology and Head \& Neck Surgery, 9, 133-140.

https://doi.org/10.4236/ijohns.2020.94017

Received: May 7, 2020

Accepted: June 29, 2020

Published: July 2, 2020

Copyright $\odot 2020$ by author(s) and Scientific Research Publishing Inc. This work is licensed under the Creative Commons Attribution International License (CC BY 4.0).

http://creativecommons.org/licenses/by/4.0/

\begin{abstract}
Lymphatic malformation (ML), formerly called cystic lymphangioma is a benign hamartomatous tumor of lymphatic vessels. The onset of lymphangiomas is either at birth (60\% to $70 \%$ ) or up to two years of age $(90 \%)$ and rare in adults. These malformations can occur in any region of the body, Lymphangiomas have marked predilection for the head and neck region $(50 \%$ $70 \%)$. The most common location in the mouth is the dorsum of tongue. If the positive diagnosis is generally easy, the therapeutic management remains controversial. We report the clinical case of a 23-year-old adult patient with cystic lymphangioma on the floor of the oral cavity extending gradually to the right submandibular region. The clinically suspected tumor was thoroughly explored using tomodensitometry. The treatment consisted of complete resection by a cervicotomy with histological examination confirming the macroscopic diagnosis of cystic lymphangioma. Follow-up at 3 years showed no recurrence.
\end{abstract}

\section{Keywords}

Cystic Lymphangioma, Oral Cavity, The Floor of the Oral Cavity, Submandibular Regio

\section{Introduction}

Lymphangioma is a benign hamartomatous tumor of lymphatic vessels, which is localized to head and neck region in about $75 \%$ of cases [1], when oral cavity is affected, the most common location is dorsum of the tongue, however, this le- 
sion is exceptionally reported at the level of the oral floor [1]. The onset of lymphangiomas is either at birth (60\% to $70 \%)$ or up to two years of age (90\%) and rare in adults [2]. They are believed to arise from lymph sac sequestration and enlarge due to inadequate drainage, from lack of communication with the central lymphatic channels or excessive secretion of lining cells [3]. Three variants have been described for these lymphangiomas [1] [4]: capillary, cavernous and cystic lymphangioma. Clinically, lymphangiomas are slow growing, painless soft tissue mass. The clinical appearance of lymphangioma depends on the extension of the lesion. Superficial lesions consist of elevated nodules with pink or yellowish color or seen as transparent grouped vesicles, which can be red or purple due to secondary hemorrhages. Deeper lesions are described as soft, diffuse masses with normal color [2].

The treatment of lymphangioma depends upon their type, size, and involvement of anatomical structures. Various treatment modalities were advocated [5]. Surgical excision is mostly indicated when vital structures are not involved. Procedures such as radiation therapy, cryotherapy, electrocautery, sclerotherapy, steroid administration, embolization, ligation, and laser surgery have also been proposed to treat lymphangiomas [5].

The following case report is of adult patients with Cystic lymphangioma on the floor of the oral cavity extending to the right submandibular region and its management.

\section{Case Report}

A 23-year-old man, patient presented with two years' history of right submandibular painless swelling which increased insidiously in volume, Patient also reported difficulty in swallowing and chewing due to growth, without compressive sign. On examination, a diffuse swelling on the right submandibular region of size approximately $8 \mathrm{~cm} \times 6 \mathrm{~cm}$, without significant change in surface texture or color. On palpation, regular and well limited mass of right submandibulare region, nontender and there were no palpable pulsations felt. Intraoral hard tissue examination revealed caries, the pressure of the mass of which resulted in an upward expansion of the mucous membrane of the floor of the oral cavity, without Reduction of tongue movement nor loss of sensory or motor functions. Based on the history and clinical feature a provisional diagnosis of lymphangioma of was made.

Cervical computed tomography confirmed the cystic nature of the swelling located at the level of the floor of the oral cavity extended below right angulomandibular, well limited, thin wall, unmodified after contrast and measuring 81 $\times 80 \times 70 \mathrm{~mm}$ in diameter, pushing hyoid bone, pharynx, as well as the tongue above (Figure 1). The patient underwent a right cervicotomy which allowed complete removal of this mass (Figure 2).

the mass extracted is of cystic nature (Figure 3), of oval shape with thick wall, of regular surface with clear limits; it measured $80 \mathrm{~mm}$. The histopathological study made the diagnosis of a cystic lymphangioma. The patient progressed well 
postoperatively. Regular monitoring did not reveal any recurrence with a three-year follow-up.

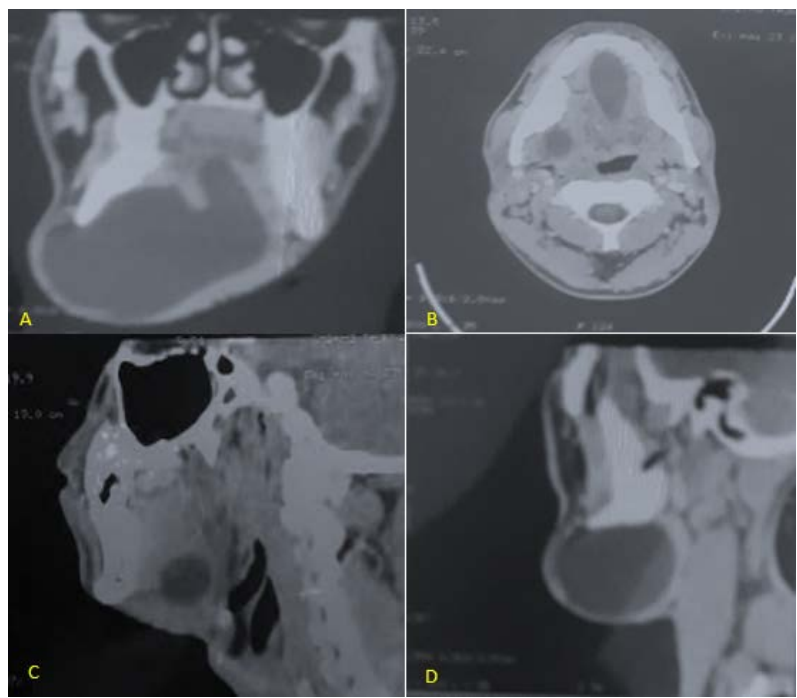

Figure 1. Cervical CT in coronal section (A) axial section (B) sagital section (C): Hypodense mass cystic nature sitting at the level of the buccal floor extended below right angulomandibular, well limited, thin wall, unmodified after contrast and measuring $81 \times 80 \times 70 \mathrm{~mm}$ in diameter.
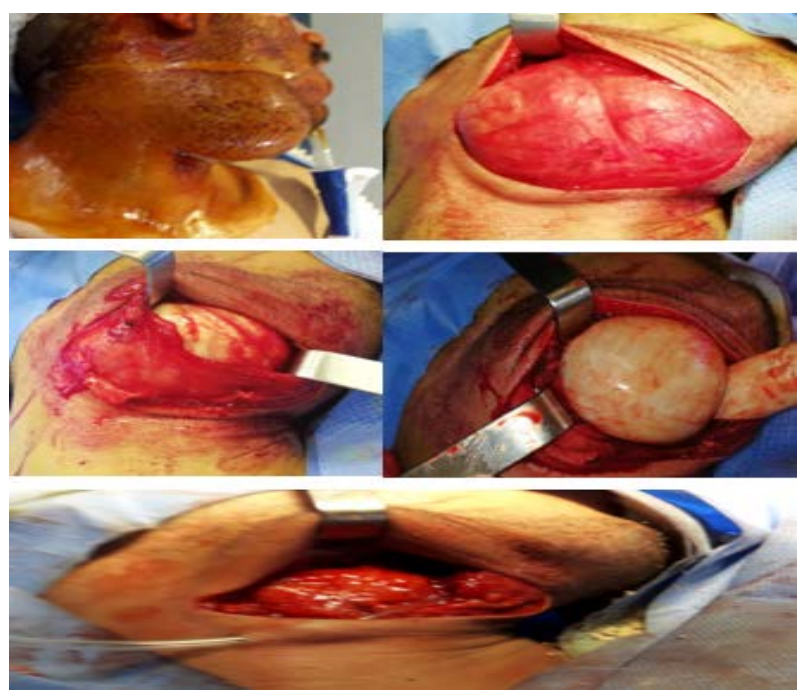

Figure 2. Operative view showing the entire excision of the tumor mass.

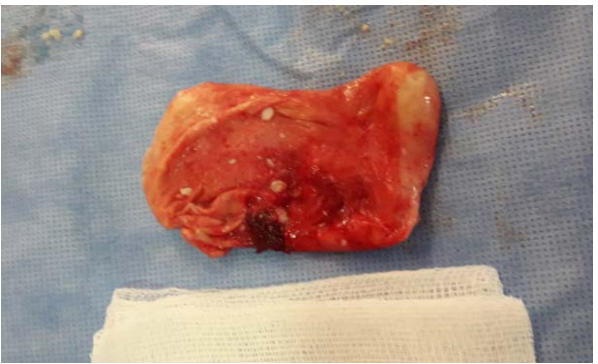

Figure 3. The tumor mass of cystic lymphangioma. 


\section{Discussion}

Lymphangiomas are a heterogeneous group of benign vascular malformations of the lymphatic system composed of cystically dilated lymphatics. It has also been called a malformation, a hamartoma, and an embryonic tumor [1]. The definition of lymphangioma, first described in 1828 by Redenbacher (apud Martinot, 1997), still controversial today. They neither become malignant nor have a familial tendency [6]. Lymphangiomas are believed to arise from lymph sac sequestration and enlarge due to inadequate drainage, from lack of communication with the central lymphatic channels or excessive secretion of lining cells [7] [8]. $65 \%$ to $75 \%$ of lesions are present since birth. About $90 \%$ of these develop before the age of 2 years, their occurrence in adults is very rarely observed [9] [10]. There is no sign of racial predominance and also equal sex incidence reported in most of the studies [2]. Lymphangiomas have a marked predilection for the head and neck region, which accounts for about $75 \%$ of all cases [9]. At the level of the oral cavity, the tongue is the main site of these lesions, moreover the floor of the oral cavity is very rarely concerne [11].

The classifications of the lymphangioma are not standardized. Traditionally, they have been divided into four categories based on histologic appearance as-: Lymphangioma simplex (composed of small thin-walled lymphatics), Cavernous lymphangioma (comprised of dilated lymphatic vessels with surrounding adventitia), Cystic lymphangioma (consisting of huge, macroscopic lymphatic spaces surrounded by fibrovascular tissues and smooth muscles), Benign lymphangioendothelioma (lymphatic channels appear to be dissecting through dense collagenic bundles) [12]. These categories are somewhat artificial and many lesions are combinations of all categories. Microcystic lymphangioma consists of cysts measuring less than $2 \mathrm{~cm}$ in size, whereas the size of cysts in case of macrocystic lymphangioma is more than $2 \mathrm{~cm}$. The mixed lymphangioma is characterized by cysts of variable sizes, i.e. some cysts are more than $2 \mathrm{~cm}$ in size and others are less than $2 \mathrm{~cm}$ [12]. In the macro-cystic forms, the swelling is rather of subcutaneous seat, soft, not pulsatile, being able to be firm in places, movable compared to the skin whereas it seems fixed to the deep planes. In microcystic forms, the swelling is quite firm, appearing to be attached to the skin, due to the invasion of the skin and subcutaneous tissues, which gives them a more disturbing character [13].

A classification of the lymphangioma of head and neck on the base of anatomical involvement had been proposed by De Serres LM (lymphatic malformation): 1) Stage/class I: infrahyoid unilateral lesions; 2) Stage/class II: suprahyoid billateral lesions; 3) Stage/class III: suprahyoid or infrahyoid unilateral lesions; 4) Stage/class IV: suprahyoid bilateral lesions; 5) Stage/class V: suprahyoid or infrahyoid bilateral lesions; 6) Stage/class IV: infrahyoid bilateral lesions [14].

Cystic lymphangioma can be asymptomatic, appearing in the form of a soft, regular and well limited swelling or manifesting itself as a result of complications related to the compression and repression of neighboring structures: obstruction 
of upper airways (sometimes leading to the practice of evacuative puncture, tracheal intubation or even a tracheostomy) [15] [16], pain, tongue's extrusion, sialorrhea, deformity of jaws, as well as difficulties in mastication, speech, and during oral hygiene, dysphagia, peripheral neurological disorders, secondary infection with fistulization of the skin or bleeding-ntracystic [17].

Imagistic studies are important for the confirmation of the diagnosis [18]. Ultrasound is the first line examination to show the cystic tumor in the form of a very limited hypoechoic mass. Computed tomography (CT) is a great contribution to the pre-therapeutic assessment of cystic lymphangioma, it makes it possible to appreciate the appearance of the tumor, its limits and to analyze the extensions towards the parotid, para-pharyngeal and mediastinal regions, which could modify the therapeutic protocol. In macro cystic forms, the mass appears relatively homogeneous, of essentially liquid density and of clear contours. It often has internal partitions that are difficult to highlight. As a rule, the mass does not gain contrast. Peripheral contrast enhancement can be observed during a local inflammatory complication. In the microcystic forms, the difficulties reside in the absence of clear limits, because these malformations creep in between the various elements of the deep planes and the neighboring organs. Some authors consider Magnetic resonance imaging (MRI) as the best test to assess the extension of Lymphangioma. According to them, this is the benchmark exam [19] [20] [21]. In fact, MRI makes it possible to perform a three-dimensional study of the region concerned better than CT, especially in the case of extension to the floor of the oral cavity, to the deep spaces of the face or in the case of parotid localization. It also makes it possible to specify the relationships with the aerodigestive axis. As for the puncture for cytological examination, it is not recommended due to the risk of septic inoculation and hemorrhage [22].

However, it is interesting in the case of an extensive compressive lymphangioma, thus making it possible to relieve skin tension in the event of an abrupt increase in tumor volume or to decrease laryngo-tracheal compression. Imaging also makes it possible to make the differential diagnosis with other cervico-facial lesions of a cystic nature, such as: bronchial cyst, thymic cyst, cyst of the thyreoglossal tract, collected abscess, hematoma, tumors necrotic, cystized teratoma [18].

The treatment of lymphangioma depends upon their type, size, involvement of anatomical structures and infiltration to the surrounding tissues 4 as well as the risk of complications. Microcystic lesions do not respect tissue planes, are diffuse and difficult to eradicate, whereas macrocystic lesions are localized and easily excised. The most effective treatment is surgery, for most authors, once the operative indication is given, the lymphangiomas must be operated as soon as possible without expecting a possible spontaneous regression (16\% of cases) [7] [10] [23] [24] and without waiting complications. when vital structures are not involved and the aims are to restore adequate breathing and swallowing, The goal of surgery is to have a complete excision with preservation of all cervical vascular, neurological and glandular structures while respecting the aesthetic 
side [10] [15]. This excision surgery is mainly recommended in cystic lymphangiomas limited to one or two cervical regions, in microcystic or mixed forms, in mono or paucikystic forms limited to the neck and in residual lymphangiomas after sclerotherapy.

However surgical complications, which occur in $19 \%$ to $33 \%$ of the cases, include formation of hematoma, lymphocele, scar, abscess, infection, wound dehiscence and nerve palsy (6\% to $76 \%$ of cases) [25] [26]. According to the different series, the nerves most often affected are the mental branch of the facial (10\% to $33 \%)$ [10] and the spinal nerve.

The various treatment modalities for lymphangioma are radiation therapy, cryotherapy, electrocautery,sclerotherapy, steroid administration, embolization and ligation, laser surgery with Nd-YAG9-11, $\mathrm{CO}_{2}$, and radiofrequency tissue ablation technique [7]. Nd-YAG laser surgery has become widely preferred because of its advantages as less bleeding and edema versus standard methods of surgical resection. Sclerosing agents are ineffective, probably as a result of the discontinuous basement membrane of the lymphatic vessels [27]. In choosing the ablative therapy of lymphangiomas, the exact knowledge of the anatomy, and spread of lesions are very important.

Recurrence is common because of its infiltrative nature. According to the study conducted by Orvidas and Kasperbauer, the recurrence rate for lymphangiomas was 39\% [28]. The high percentage of oral involvement correlated with a high degree of persistent disease. The most common sites for recurrence are the tongue and hypopharynx and/or larynx in this case report, we opted for their surgical removal. After 3 year of follow-up, no sign of lesion relapse was identified.

\section{Conclusion}

Cystic lymphangioma is a rare benign tumor, but potentially serious by its progressive characteristics and its dissecting tendency, usually known by its occurrence at a very early age. It is more frequently encountered at the cervical level. This tumor is exceptionally described in an adult at the level of the floor. Of the oral cavity surgery is the treatment of choice. It is indicated for the first intention in localized and diffuse macrocystic forms and in microcystic forms. Full excision is the only guarantee to avoid recurrences. It is important that the patient understands that this pathology is benign and that it does not present a risk of malignant transformation.

\section{Source of Funding}

The author declares that there is no source of funding among all authors.

\section{Consent}

Since identification of the patient from submitted material is not possible, written consent for publication was not obtained. 


\section{Conflicts of Interest}

The authors declare no conflicts of interest regarding the publication of this paper.

\section{References}

[1] Daver, G., Bakgchi, G.D., Patil, A.S., Shaikh, A.S., Mokashi, N.P., Mogal, H.D. and Joshi, N.Y. (2005) Cystic Lymphangioma in an Adult. Bombay Hospital Journal, 47, 90-93.

[2] Bhayya, H., Pavani, D., Avinash Tejasvi, M.L. and Geetha, P. (2015) Oral Lymphangioma: A Rare Case Report. Contemporary Clinical Dentistry, 6, 584-587. https://doi.org/10.4103/0976-237X.169851

[3] Goswami, M., Singh, S., Gokkulakrishnan, S. and Singh, A. (2011) Lymphangioma of the Tongue. National Journal of Maxillofacial Surgery, 2, 86-88. https://doi.org/10.4103/0975-5950.85862

[4] Un Guner, M., Aydin, A. and Celik, F. (2006) Cystic Hygroma in Adults: Report of Two Cases. The Medical Journal of Bakırköy, 2, 101-103.

[5] Alqahtani, A., Nguyen, L.T., Flageole, H., Shaw, K. and Montreal, J.M.L. (1999) 25 Years' Experience with Lymphangiomas in Children. Journal of Pediatric Surgery, 34, 1164-1168. https://doi.org/10.1016/S0022-3468(99)90590-0

[6] Kheur, S.M., Routray, S., Ingale, Y. and Desai, R.S. (2011) Lymphangioma of Tongue: A Rare Entity. Indian Journal of Dental Advancements, 3, 635-637. https://doi.org/10.5866/3.3.635

[7] Rajendra, K., et al. (2013) Management of Giant Cystic Lymphangioma in an Infant. Journal of Clinical and Diagnostic Research, 7, 1755-1756. https://doi.org/10.7860/JCDR/2013/5418.3256

[8] Santos, B.C., Lemos, C.P.L., Ribeiro, B.F., Iglesias, D.P.P., Vasconcelos, R.G. and de Medeiros, A.M.C. (2011) Oral Lymphangioma: Case Report. RSBO, 8, 352-356.

[9] Livesey, J.R., Soames, J.V., et al. (1992) Cystic Lymphangioma in the Adult Parotid. The Journal of Laryngology \& Otology, 106, 566-568. https://doi.org/10.1017/S0022215100120171

[10] Rakotosamimanana, J., Vololonantenaina, C.R., Ratovoson, H., Ahmad, A. and Razafindramboa, H. (2000) Lymphangiome kystique Cervico-médiastinal: A propos d'un cas et revue de la littérature. Archives de P Institut Pasteur de Madagascar, 66, 61-64.

[11] Ali, E., Karim, N., Hicham, A. and Mohamed, Z. (2016) Cystic Lymphangioma on the Floor of the Oral Cavity Extending to the Submandibular Region in Adult Patients. The Pan African Medical Journal, 24, 202. https://doi.org/10.11604/pamj.2016.24.202.8395

[12] Keda, H., Fujita, S., Nonaka, M., Uehara, M., Tobita, T. and Inokuchi, T. (2006) Cystic Lymphangioma Arising in the Tip of the Tongue in an Adult. International Journal of Oral and Maxillofacial Surgery, 35, 274-276. https://doi.org/10.1016/j.ijom.2005.07.009

[13] François, M., Guillou, C., Depondt, J., Aboucya, J.P., Contencin, Ph. and Narcy, Ph. (1986) Les lymphangiomes cervico-faciaux chez l'enfant. Ann Otolaryng, 103, 113-117.

[14] Stanescu, L., Georgescu, L.E.F., Simionescu, C. and Georgescu, I. (2006) Lymphangioma of the Oral Cavity. Romanian Journal of Morphology and Embryology, 47, 373-377.

[15] Nicollas, R., Roman, S. and Triglia, J.M. (2006) Chirurgie des malformations 
congénitales du cou chez l'enfant. Encycl Med Chir, 46-480, 12 p.

[16] Best, S.R., Coelho, D.H., Ahrens, W.A., Atez, G. and Sasaki, C.T. (2008) Laser Excision of Multiple Esophageal Lymphangiomas: A Case Report and Review of the Literature. Auris Nasus Larynx, 35, 300-303. https://doi.org/10.1016/j.anl.2007.07.016

[17] Guruprasad, Y., Chauhan, D.S., et al. (2012) Cervical Cystic Hygroma. Journal of Maxillofacial and Oral Surgery, 11, 333-336. https://doi.org/10.1007/s12663-010-0149-x

[18] Romeo, V., Maurea, S., Guarino, S. and Sirignano, C. (2013) Case of Lower-Neck Cystic Lymphangioma: Correlative US, CT and MR Imaging Findings. Quantitative Imaging in Medicine and Surgery, 3, 224-227.

[19] Nancy, M.B., Chantal, M.G., Jose, M.M., Yutaka, S., Diane, K.B. and Richard, J.H.S. (2002) Management of Lymphatic Malformations: If, When, and How. Operative Techniques in Otolaryngology_Head and Neck Surgery, 13, 85-92. https://doi.org/10.1053/otot.2002.31396

[20] Wierzbicka, E., Herbreteau, D., Robert, M. and Lorette, G. (2006) Malformations Lymphatiques Kystiques. Annales de Dermatologie et de Vénéréologie, 133, 597-601. https://doi.org/10.1016/S0151-9638(06)70973-5

[21] Wong, K.T., Lee, Y.Y.P., King, A.D. and Ahuja, A.T. (2008) Imaging of Cystic or Cyst-Like Neck Masses. Clinical Radiology, 63, 613-622.

https://doi.org/10.1016/j.crad.2007.12.007

[22] Isenberg, S.F. (1995) Cystic Hygroma: Recurrence in an Adult 34 Years Later. American Journal of Otolaryngology, 16, 347-349. https://doi.org/10.1016/0196-0709(95)90065-9

[23] Grabb, W.C., Dingman, R.O., Oneal, R.M. and Dempsey, P.D. (1980) Facial Hamartomas in Children: Neurofibroma, Lymphangioma and Hemangioma. Plastic and Reconstructive Surgery, 66, 509-527. https://doi.org/10.1097/00006534-198010000-00003

[24] Seashore, J.H., Gardiner, L.J. and Ariyan, S. (1985) Management of Giant Cystic Hygroma in Infants. The American Journal of Surgery, 149, 459-465. https://doi.org/10.1016/S0002-9610(85)80040-4

[25] Lei, Z.M., Huang, X.X., Sun, Z.J., Zhang, W.F. and Zhao, Y.F. (2007) Surgery of Lymphatic Malformations in Oral and Cervicofacial Regions in Children. Oral Surgery, Oral Medicine, Oral Pathology, Oral Radiology, and Endodontology, 104, 338-344. https://doi.org/10.1016/j.tripleo.2006.12.025

[26] Hartl, D.M., Roger, G., Denoyelle, F., Nicollas, R., Triglia, J.M. and Garabedian, E.N. (2000) Extensive Lymphangioma Presenting with Upper Airway Obstruction. Archives of Otolaryngology_Head \& Neck Surgery, 126, 1378-1382. https://doi.org/10.1001/archotol.126.11.1378

[27] Ogita, S., Tsuto, T., Nakamura, K., Deguchi, E. and Iwai, N. (1994) OK-432 Therapy in 64 Patients with Lymphangioma. Journal of Pediatric Surgery, 29, 784. https://doi.org/10.1016/0022-3468(94)90370-0

[28] Orvidas, L.J. and Kasperbauer, J.L. (2000) Pediatric Lymphangiomas of the Head and Neck. Annals of Otology, Rhinology, and Laryngology, 109, 411-421. https://doi.org/10.1177/000348940010900412 